\title{
Organ donation in South Africa - a call to action
}

In this issue of the SAJCC, Crymble et al..$^{[1]}$ correctly point out that there is a desperate need for organ donors in South Africa (SA). Their article highlights the integral role of nurses in the organ donation process, ${ }^{[2]}$ and elegantly shows that nurses would welcome a greater role, while at the same time noting that expanded education efforts are desperately needed.

Despite our place in history for performing the first heart transplant, ${ }^{[3]}$ SA organ donation rates do not compare well with other countries. Our deceased donor rate is $<3$ per million population. Spain is the world leader in deceased organ donation, with a rate approaching 40 per million population and Brazil achieves a rate of 14 per million population. ${ }^{[4]}$

Many people see living-related donation as the way forward, yet living-related donation is only an option for certain organ transplants. The majority of patients in need of an organ do not have a suitable living donor. Living donation also exposes donors to a degree of risk which deceased donors by definition do not have, since they are always certified legally dead through a rigorous testing process. Under SA law, certification of brain death is required to be performed by two doctors, of whom one is required to have $>5$ years of experience and both should be completely independent of the transplant team. ${ }^{[5]}$

The reasons for SA's low deceased donation rate are multiple. The lack of awareness and knowledge among both the public and medical professionals about brain death and organ donation needs to be addressed. ${ }^{[6]}$ Free, open-access online educational resources, such as the University of Cape Town's course 'Organ Donation: From Death to Life', have been developed to improve training and awareness about brain death and organ donation. ${ }^{[7]}$

The SA government's healthcare policy, which is rightly focused on primary healthcare interventions as a cost-effective strategy to improve the health of the population, ${ }^{[8]}$ should not neglect transplantation. Although it is not prioritised as a major health need, transplantation activity is a reflection of the whole healthcare system. One can only be assessed as a potential organ donor when all treatment options have been exhausted and the clinical team has left no stone unturned. The family can only be approached for consent for donation when they have been adequately counselled about the clinical situation. If this is not done well, consent will not be given and without consent there can be no organ donation. As such, organ donation rates can and should be used as a measurable healthcare outcome.

In SA, the consent rate for deceased organ donation at Groote Schuur Hospital for 2017 was $18 \%$ at the time of publication of this editorial, in other words $82 \%$ of families opt not to support organ donation. Even in countries where consent is presumed, the family is always counselled. Spain has a $16 \%$ refusal rate based on family objections. It is important to note that signing onto the organ donor registry in SA (which only 200000 of 53 million people have done) does not constitute consent and the family will always be approached to provide this. Evidence supports that consent for organ donation should be obtained by specially trained individuals, where available, and not the treating clinical team, with the request for consent made at an appropriate moment. ${ }^{[9]}$

Presumed consent is often touted as the reason for Spain being so successful. However, it was only 10 years after the law was put in place that a national body was formed with oversight of organ donation, after which the system improved. Together with adequate access to beds in the intensive care unit (ICU), the availability of transplant coordinators in each ICU, and continual quality assurance and education activities, the Spanish model for transplantation is now a role model for other countries wanting to improve organ donation rates. ${ }^{[10]}$

Cultural reasons are often blamed for low donation rates, yet there is no society, religion or culture that does not champion helping our fellow man. 'Ubuntu' is a word that embodies all that organ donation represents. There is a perception that religions such as Judaism and Islam are opposed to organ donation; however, religious scholars of both these religions have come out in support of organ donation. ${ }^{[11,12]}$ Culture is not static and evolves over time; therefore it is essential that we as healthcare professionals engage with our SA communities to allow organ donation to become the norm. The most effective slogan is 'If you needed an organ, would you accept one?'.[13] None of the major cultures or religions forbid receiving an organ.

Brain death is a relatively rare event. Mechanical ventilation must have been instituted and the condition progressed to one where recovery is impossible. Only $1 \%$ of all deaths are able to be considered for possible organ donation. ${ }^{[14]}$ For this reason, every opportunity for organ donation needs to be explored when appropriate - this does not always happen. A UK review of potential organ donors in 2011/2012 showed that $26 \%$ of patients who were potentially brain dead as per their hospital notes never proceeded to formal brain death testing, and of those that were certified, $7 \%$ of families were not approached for consent. ${ }^{[15]}$

There is no mandated requirement for discussion of a potential donor with a transplant team in SA, nor is there any system in place to audit the standard of our end-of-life care discussions to ensure that all families are given the opportunity to support organ donation. Crymble et al. ${ }^{[1]}$ have illustrated a possible intervention to improve our organ donation system by empowering nurses, who deal intimately with the family during the dying process and beyond, with a role in the referral of patients for organ donation.

Such efforts need to be made on a national level across both public and private healthcare institutions. Pioneering efforts in SA in HIV-toHIV transplantation, ${ }^{[16]}$ donation after circulatory death, and splitting donor livers ${ }^{[17]}$ are all still limited by a lack of deceased organ donors. Ultimately, organ donation always comes down to a treating clinical team discussing a potential donor with the transplant team and a family deciding to support organ donation.

\section{David Thomson}

Critical Care Specialist and Transplant Surgeon, Department of Critical Care and Transplant Unit, Groote Schuur Hospital, University of Cape Town, South Africa

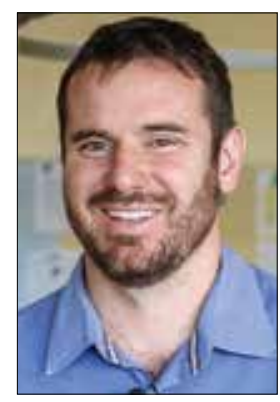

S Afr J Crit Care 2017;33(2):36-37. DOI:10.7196/SAJCC.2017.v33i2.352

1. Crymble K, Etheredge HR, Fabian J, Gaylard P. Nurses' knowledge about and attitude towards organ donation in state and private hospitals in Johannesburg, South Africa - 2015 to 2016. S Af J Crit Care 2017;33(2):52-57. https://doi.org/10.7196/SAJCC.2017.v33i2.322

2. Domínguez-Gil B, Delmonico FL, Shaheen FA, et al. The critical pathway for deceased donation: Reportable uniformity in the approach to deceased donation. Transplant Int 2011;24(4):373-378. https://doi.org/10.1111/j.1432-2277.2011.01243.x

3. Barnard CN. Human cardiac transplant: An interim report of a successful operation performed at Groote Schuur Hospital, Cape Town. S Afr Med J 1967;41(48):1271-1274.

4. Irodat. International Registry in Organ Donation and Transplantation 2015 http://www.irodat org/img/database/pdf/NEWSLETTER2016_SecondEdition.pdf (accessed 15 September 2017). 
5. McQuoid-Mason D. Human tissue and organ transplant provisions: Chapter 8 of the National Health Act and its regulations, in effect from March 2012 - what doctors must know. S Afr Med J 2012;102(9):730-732. https://doi.org/10.7196/samj.6047

6. Sobnach S, Wiese KR, Tselanyane ME, Borkum M, Kahn D, Segobin R. Medical student knowledge about brain death: A South African contribution. Transplant Proc 2016;48(6):1904 1906. https://doi.org/10.1016/j.transproceed.2016.04.010

7. University of Cape Town. Organ Donation: From death to life 2017. https://www.coursera.org/ learn/organ-donation (accessed 15 September 2017)

8. Mayosi BM, Benatar SR. Health and health care in South Africa - 20 years after Mandela. N Eng J Med 2014;371(14):1344-1353. https://doi.org/10.1056/nejmsr1405012

9. Hulme W, Allen J, Manara AR, Murphy PG, Gardiner D, Poppitt E. Factors influencing the family consent rate for organ donation in the UK. Anaesthesia 2016;71(9):1053-1063. https://doi org/10.1111/anae.13535

10. Rodríguez-Arias D, Wright L, Paredes D. Success factors and ethical challenges of the Spanish model of organ donation. Lancet 2010;376(9746):1109-1112. https://doi.org/10.1016/s0140 6736(10)61342-6
11. Lavee J, Ashkenazi T, Stoler A, Cohen J, Beyar R. Preliminary marked increase in the national organ donation rate in Israel following implementation of a new organ transplantation law. Am J Transplant 2013;13(3):780-785. https://doi.org/10.1111/ajt.12001

12. Robson NZMH, Razack AH, Dublin N. Organ transplants: Ethical, social, and religious issues in a multicultural society. Asia Pacific J Pub Health 2010;22(3):271-278. https://doi org $/ 10.1177 / 1010539509357446$

13. Team BI. Applying behavioural insights to organ donation: Preliminary results from a randomised controlled trial. London: Cabinet Office; 2013.

14. DonateLife. Australian Donation and Transplantation Activity Report 2016 - 2017 http://www. donatelife.gov.au/sites/default/files/Australian Donation and Transplantation Activity Report 2016.pdf (accessed 15 September 2017).

15. NHS. Potential Donor Audit 2011 - 2012. https://nhsbtdbe.blob.core.windows.net/umbracoassets-corp/3180/pda_report_1112.pdf (accessed 15 September 2017).

16. Muller E, Barday Z, Mendelson M, Kahn D. HIV-positive-to-HIV-positive kidney transplantation - results at 3 to 5 years. N Eng J Med 2015;372(7):613-620. https://doi.org/10.1056/nejmoal408896

17. Loveland J, Britz R, Joseph C, et al. Paediatric liver transplantation in Johannesburg revisited: 59 transplants and challenges met. S Afr Med J 2014;104(11):799-802. https://doi.org/10.7196/samj.8627 